\title{
BUENO, ¿Y QUÉ ES LA UNIVERSIDAD?
}

Humberto Giannini Î̃iguez 


\section{HUMBERTO GIANNINI ÍÑIGUEZ}

Estudió Hermenéutica y Filosofía de la Religión en la Universidad de Roma. En 1998 fue elegido miembro de número de la Academia Chilena de la Lengua, donde ocupa el sillón $\mathrm{N}^{\circ}$ 12. Premio Nacional de Humanidades y Ciencias Sociales 1999, Premio Consejo Nacional del Libro y la Lectura 2008, categoría Ensayo, por La metafísica eres tú y Premio Altazor de Ensayo 2009 por el mismo título. 


\section{BUENO, ¿Y QUÉ ES LA UNIVERSIDAD?}

Las siguientes reflexiones no pretenden aclarar una situación histórica que me parece bastante compleja, sino invitar al lector bien dispuesto y que cuente con el material adecuado, a que confirme o desmienta algo que a la distancia se nos presenta como el primer ocaso de la universidad en Occidente. A mi entender aquel fracaso ofrece una fuerte analogía con la situación en que se encuentran en nuestros días los llamados "estudios superiores". Y es esta eventual analogía la que pretendemos comentar.

I. A la pregunta de nuestro título cabe contestar, sin equivocarnos demasiado, que Universidad es la institución social que ofrece a la ciudadanía los más altos estudios. Pero, se comprende, tal respuesta no hace sino aplazar una respuesta positiva. Si es que la hay.

Si quisiéramos, en cambio, poner las cosas en términos positivos, a partir, por ejemplo, de la expresión primitiva de "universitas", tendríamos que reconocer que su significado inicial es muchísimo más modesto del que va a adquirir en menos de un siglo.

En el lenguaje común de los siglos IV y V por "universitas" se entendía simplemente la corporación, el gremio de aquellos que "hacen lo mismo", el mismo oficio': hacer zapatos, curar enfermos, enseñar o aprender gramática en una escuela parroquial, etc. Y así como en una época fue común decir "la universidad de los zapateros", poco tiempo después empezará a ser común decir también "la universidad de los estudios". En Italia, país que conserva intactas algunas expresiones comunes del latín, se sigue llamando "università degli studi" ('Universidad de los estudios') a la misma que nosotros llamamos genéricamente "Universidad".

Una circunstancia histórica ocasional va a producir la asociación lingüística que teñirá la palabra "universitas" con un tinte esencial, definitivamente filosófico. En aquel tiempo (s. VI) circula por Inglaterra, Francia e Italia un pequeño y explosivo opúsculo de Porfirio, el "Isagoge" (que significa "Introducción") -Boecio (480-524) lo traduce al latín y con esta traducción se abre el famoso y largo debate acerca de los universales, debate que durará siglos y pondrá en pugna todo el naciente ámbito de la filosofía medieval ${ }^{2}$. Se comprende, no enfrentaremos aquí el problema mismo. Solo nos interesa destacar esto: fuera de las variadas soluciones que se dieron al problema, la palabra "universitas" empieza a asociarse a la congregación de intelectuales que discuten acerca de la existencia o inexistencia de los universalesDesde fines del siglo XII y en los siglos

1. de Sevilla, I., Etimologías, III, pág.3.

2. El problema es si existió primero la idea de una cosa existente y luego la cosa misma, o si la idea aparece después de la cosa. En la existencia de los objetos fabricados la respuesta es clarísima: primero existió, por ejemplo, la idea de la cítara y luego su fabricación. Pero respecto de las cosas de la naturaleza la respuesta no es tan simple. Para "los realistas" cristianos, primero fue en Dios la idea de un Adán posible y luego el Adán real. Pero en esto -que es muchísimo más complejo de lo que lo presentamosse jugaban muchas cosas esenciales que aquí pasamos por alto. 
XIII y XIV ya se han constituido las grandes universidades de la Europa cristiana: la de Bolonia -tal vez, la primera- (1088), la de Oxford (1096), famosa por abrirse muy tempranamente a las ciencias físicas ${ }^{3}$ y La Universidad de Paris (1090).

La Iglesia va construyendo su cuerpo dogmático en gran parte a través de la discusión universitaria -quaestiones disputae- y, en cierto sentido, liga todo lo que concierne al saber y al hacer humanos a la dogmática que se ha levantado con la asimilación del lenguaje técnico de la lógica aristotélica.

Ocurre en el siglo XV un hecho que va a conmover durante siglos el edificio espiritual de la Iglesia romana: un desmentido científico radical a la cosmovisión geocéntrica. La excentricidad del planeta Tierra, propuesta por las investigaciones de Nicolás Copérnico (1473-1543) y defendidas posteriormente por Galileo Galilei (1564-1642), fue un golpe que conmovió por más de dos siglos a la Iglesia y a su sólida estructura antropocéntrica ligada a la Universidad. ¿Qué estaba pasando en la historia viva de Occidente que ya no estaba pasando por las aulas universitarias?

Recordemos que la Universidad nació al alero de las catedrales -como escuelas catedralicias- con el fin primordial de instalar en la vida ciudadana los cimientos espirituales de la fe que profesaba la población. En esta tarea la Iglesia docente se fue encontrando con los grandes maestros de la cristiandad, empezando por San Agustín y Diógenes el Areopagita, y así se fue acercando -no siempre proponiéndoselo- a los grandes maestros de la Antigüedad griega: Platón y su obra El Timeo, Aristóteles: Las Categorías; y a pensadores romanos como Cicerón y Marco Aurelio, etc.

Así la tosca mentalidad de los tiempos empezaba a entender los grandes temas y a intercambiar opiniones sobre las dificultades que chocaban con la fe a propósito de dogmas como el de la creación ex nihilo y el de la salvación final, entre otros. Y fue así cómo en el estudio de los textos, en la confrontación de opiniones y en la elaboración de métodos de estudio y de argumentación, algunas escuelas catedralicias, que modestamente empezaron a enseñar las materias más elementales para una comunidad de experiencias, se convirtieron en grandes universidades.

Por su parte, la Iglesia construye su cuerpo dogmático en gran medida a través de la discusión universitaria -las famosas quaestiones disputae-, y en cierto sentido liga todo lo que concierne al saber y al hacer humanos a una dogmática que se ha venido construyendo con la asimilación del lenguaje y de la lógica aristotélicas.

En el siglo XVI el contrapunto entre razón y fe -entre historia profana e historia sagrada, entre evento físico y milagro- se vuelve explosivo, en un grado que hoy no es imaginable. Y no solo a nivel científico y académico, sino también a nivel de la sensibilidad cotidiana. Pensemos, por otra parte, que en el mundo del trato diario las lenguas regionales habían alcanzado tal madurez y vitalidad que el latín eclesiástico y universitario fuera de estos dominios quedaba reducido a la obligatoriedad de los escritos legales y a la pedantería de los magistrados. Galileo, que fue un espléndido escritor, se burla de la escolástica y sus latinazgos a través de un personaje de su invención (Simplicio). En

3. Famosas las investigaciones de Grosseteste en torno a la luz. 
Italia, Francia y España ya se expresaban en lengua vulgar la majestuosidad y la gracia de la poesía, de la picaresca y de la novela, y la frescura del habla callejera y popular.

Fue entonces cuando surgieron -o resurgieron-como por encanto en las principales ciudades de Europa, instituciones como las Academias, con una nueva idea de lo que es digno de estudio y de consideración en vistas de la dignidad humana. Muchos libros se escriben ahora con ese título: "De dignitate hominis". Y fue entonces cuando, en recuerdo de Platón, la nueva sensibilidad, amparada por reyes y príncipes poderosos, se multiplicó y se diversificó en "Academias" para enfrentar también al aristotelismo ideologizado de la Iglesia. Y no se exagera al afirmar que el fortalecimiento de las lenguas vivas, el renacimiento y difusión de las letras y de la investigación acerca de los cuerpos y de los fenómenos naturales, fueron actitudes ligadas de un modo esencial -tal vez, exclusivoal surgimiento de las Academias.

Hay un modo justo -necesario- a mi parecer, de caracterizar al Renacimiento, en general, y el italiano, en particular, poniendo atención en las inquietudes que dieron origen, a partir del "quattrocento" al surgimiento de más de 300 Academias de Arte, de Ciencia Físicas, de Humanidades, de Filosofía, de Arqueología, Academias de la Lengua (en defensa de las lenguas vernáculas, sostenidas en general por la Corona) en las principales capitales de Europa. Inquietudes que no habían encontrado acogida alguna en la institución que parecía destinada a ampararlas; en la institución que había nacido justamente a fin de superar la barbarie que siguió al derrumbe de la Roma imperial.

La historia ha sido ingrata con las Academias, al olvidar la fuerza, profundidad y extensión de su aporte al rejuvenecimiento de Europa, en la vida diaria, en el arte, en la filosofía y en la ciencia.

Puede resultar extraño al constatarlo: las Academias permanecieron y permanecen aún hoy como Academias, esto es, como instituciones en las que se reúnen regularmente -ya sea los artistas plásticos, los poetas o los científicos- con el fin de tratar libremente los problemas propios de sus respectivas disciplinas o presentar proyectos ante sus pares o simplemente compartir ideas. Por ejemplo, de la famosa Accademia della Crusca $(1582)^{4}$ salió la publicación del primer diccionario toscano, y poco después, la primera gramática de la lengua italiana. (La Real Academia Española de la lengua fue fundada por Felipe V en 1714. A ella también debemos el primer Diccionario de la lengua española).

II. Provenimos de una cultura esencialmente religiosa, que a partir de la concepción de un Hacedor omnipotente y bondadoso se infería que la criatura humana nace con una deuda de ser por el hecho de haber nacido. No pertenece a nuestra experiencia común el tener la vida como deuda de ser, ni con Dios ni con las generaciones que han hecho posible accidentalmente la nuestra.

Suele ocurrir, por el contrario, que algunos experimenten la existencia como una deuda que los otros -la sociedad, por ejemplo, o en palabras de Heidegger "los que nos

4. Arnero. 
han arrojado al mundo"- tengan una deuda de humanidad con nosotros: la deuda de no haber convertido un hecho biológico en un proyecto verdaderamente humano de lo que soy y de lo que he sido antes de ser.

¿Qué ocurre en una sociedad cuando la existencia "ya no se experimenta como un don"? ¿Si se percibe oscuramente que se ha llegado a la vida "en un mal momento" de la vida social y familiar, que se ha llegado a destiempo? ¿Que uno es el contratiempo? ¿Cuando, indefenso, se es arrojado (nuevamente) a su suerte, excluido de los bienes de la Tierra y de aquellos que constituyen posibilidades para la plenitud de la vida humana? Entonces, ¿no es posible considerar la vida, la única que conocemos, como un mal?

A millones de seres humanos que viven en condiciones similares la experiencia les ha enseñado que todavía se les debe esa vida a la que se les trajo: la deuda de convertir al individuo numérico, meramente contable, en individuo humano, en sujeto entre sujetos.

La oscura experiencia generacional de la vida que debe la sociedad al ser desvalido que se inicia en ella, hace que el planteamiento de la formación gratuita se eleve a exigencia en el plano de los derechos humanos.

Pero poco se ganaría si esta sociedad no fuera capaz, técnicamente capaz, de ofrecer la educación humanizada en la que los futuros ciudadanos están llamados a formarse.

III. ¿Por qué hoy hemos ido a mirar tan atrás en la historia de la Universidad?

Porque, a nuestro parecer, su decadencia hacia fines de la Edad Media coincide con la axiomatización de su estructura teórica (la imposición dogmática) de "lo que es superior".

En nuestro país, a partir del año 1981, con la imposición de un liberalismo darwiniano, la educación pública -desde la Universidad hasta la instrucción elemental- viene sufriendo una decadencia que hoy, a 30 años de distancia, recién empieza a percibirse en el dramatismo que realmente tiene. Y una de las razones teóricas poderosas de esta decadencia es el menosprecio a la teoría y confusión del concepto de Universidad -y de universalidad-con el ofrecimiento de profesiones cuya principal característica es su bajo costo para las instituciones que las ofrecen y de alto costo para quien la solicita, por su gran demanda.

Esta característica ha permitido a cualquier emprendedor instalar universidades que ofrecen la misma mercadería, servida por profesores explotados hasta lo indecible.

Para medir su calidad habría que preguntarse cuántas de las llamadas "universidades", a partir de 1982, cuentan con equipos de investigadores en ciencias como la física, astronomía, matemáticas, filología clásica, música, opciones lingüísticas (francés, alemán, italiano, mapuche); cuántas poseen equipos de investigación en ciencias, bibliotecas especializadas y al día; cuántas ofrecen un horario completo al número adecuado de profesores para cubrir investigación y docencia, como parece ideal. Personalmente conozco la otra cara: profesores contratados por 3 o 6 horas, y solo por meses, con una mera promesa de recontratación "en el próximo semestre"... en la eventualidad de contar con el número conveniente de alumnos. Profesores sin previsión, sin derecho a vacaciones, pero cargados de pruebas y obligaciones fuera de horario. Mártires modernos 
con 50 a 60 horas de clases para poder sobrevivir, y que, además, deben sufrir impotentes los continuos ataques de la prensa por lo que llaman su impreparación académica.

En la mayoría de esas "universidades" no hay claustro académico ni elección de autoridades y en este sentido están muy lejos de la Universidad medieval, que fue "comunidad de profesores y alumnos".

Y pese a todo esto, los consumidores de universidades pagan las tarifas más altas del planeta.

El sepulturero de la educación pública: Augusto Pinochet no llegó, sin embargo, a tener la osadía de decir que no hay cosas gratuitas en el mundo. Si gratuito es lo que nos llega o nos cae encima sin buscarlo, el mal en Chile es una de las cosas gratuitas. Y vergonzosa, además... 